\title{
The Pioneering and Unknown Stereotactic Approach of Roeder and Orthner from Göttingen. Part II: Long-Term Outcome and Postmortem Analysis of Bilateral Pallidotomy in the Pre-Levodopa Era
}

\author{
Wolfgang Hamel ${ }^{\mathrm{a}}$ Johannes A. Köppen ${ }^{\mathrm{a}}$ Dieter Müller ${ }^{\mathrm{a}}$ Marwan Hariz ${ }^{\mathrm{b}, \mathrm{c}}$ \\ Christian K.E. Moll ${ }^{d}$ Paul Krack ${ }^{\mathrm{e}}$

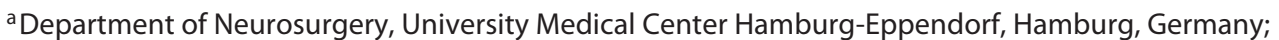

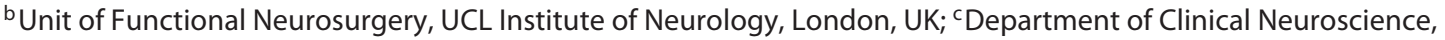 \\ Umeå University, Umeå, Sweden; ${ }^{\mathrm{d}}$ Department of Neurophysiology and Pathophysiology, University Medical \\ Center Hamburg-Eppendorf, Hamburg, Germany; ${ }^{e}$ Department of Neurology, Inselspital, University Hospital Bern, \\ Bern, Switzerland
}

\section{Keywords}

History - Stereotactic surgery - Stereotactic lesioning .

Pallidotomy · Parkinson disease · Oculogyric crisis .

Postmortem

\begin{abstract}
Before the advent of levodopa, pallidotomy was initially the most effective treatment for Parkinson disease, but it was soon superseded by thalamotomy. It is widely unknown that, similar to Leksell, 2 neurologists from Göttingen, Orthner and Roeder, perpetuated pallidotomy against the mainstream of their time. Postmortem studies demonstrated that true posterior and ventral pallidoansotomy sparing the overwhelming mass of the pallidum was accomplished. This was due to a unique and individually tailored stereotactic technique even allowing bilateral staged pallidotomies. In 1962, the long-term effects (3-year follow-up on average) of the first 18 out of 36 patients with staged bilateral pallidotomies were reported in great detail. Meticulous descriptions of
\end{abstract}

each case indicate long-term improvements in parkinsonian rigidity and associated pain, as well as posture, gait, and akinesia (e.g., improved repetitive movements and arm swinging). Alleviation of tremor was found to require larger lesions than needed for suppression of rigidity. No improvement in speech, drooling, or seborrhea was observed. By 1962, the team had operated 13 patients with postencephalitic oculogyric crises with remarkable results (mean follow-up: 5 years). They also described alleviation of nonparkinsonian hyperkinetic disorders (e.g., hemiballism and chorea) with pallidotomy. The reported rates for surgical mortality and other complications had been remarkably low, even if compared to those reported after the revival of pallidotomy by Laitinen in the post-levodopa era. This applies also to bilateral pallidotomy performed with a positive risk-benefit ratio that has remained unparalleled to date. The intricate history of pallidotomy for movement disorders is incomplete without an appreciation of the achievements of the Göttingen group.

(c) 2019 S. Karger AG, Base

\section{KARGER}

(c) 2019 S. Karger AG, Basel

E-Mail karger@karger.com

www.karger.com/sfn
Prof. Dr. Wolfgang Hamel

Klinik für Neurochirurgie, Universitätsklinikum Hamburg-Eppendorf

Martinistrasse 52

DE-20246 Hamburg (Germany)

E-Mailw.hamel@uke.de 


\section{Introduction}

Improvement in parkinsonian symptoms by pallidal lesions was first reported by Russell Meyers [1]. With the advent of the stereotactic method, and despite initial concerns with regard to pallidal lesions in Parkinson disease, pallidotomy eventually became the preferred procedure [2-8]. However, soon pallidotomy became swept away by thalamotomy. As exemplified by Krauss and Grossman [9], pallidotomy was not even mentioned in the index of the Schaltenbrand and Walker [10] opus. Mundinger [11], who had been involved in no less than several hundred pallidotomies, once wrote: “... When my friend Lauri Laitinen reintroduced pallidotomy a few years ago, I was somewhat skeptical, initially, like most of us.... None of us would ever have thought that thalamotomy would push pallidotomy to the background within only a few years...."

Superior efficacy of thalamotomy on tremor was the key factor for shifting from pallidotomy to thalamotomy. While thalamotomy may also improve rigidity, it does not improve akinesia, and isolated improvement in rigidity does not translate into improvement in function [12]. A shortcoming of most of the studies from the early days, however, is related to the fact that improvement in rigidity was typically regarded as equivalent with improvement in the "akineto-rigid" syndrome.

Beyond that, surgical issues enforced the shift from the pallidum to the thalamus. First, the risk of hemorrhage is significantly higher in the pallidum than in the thalamus. Second, the pallidal target is obliquely oriented and narrows in the posterior direction. With typical trajectories from frontolateral, the risk of inadvertent lesioning of the internal capsule is higher than in the thalamus, in particular with posterior adjustments of the target where lesioning is presumed to be optimal. Third, there is a significant risk of injury to the optic tract. Fourth, regions for the suppression of certain symptoms and somatotopy have not been delineated as clearly as in the thalamus. In contrast, the ventrolateral motor thalamus and the subthalamic region, both known for tremor alleviation, can be approached with less risk, and both regions can be covered with a straight probe and single trajectory.

After the introduction of thalamotomy, pallidotomy was considered as a second-choice target. Pallidotomy was mostly chosen as an asymmetric target contralateral to a thalamotomy in order to avoid the adverse events of bilateral thalamotomy [13]. Hitherto, it is widely unknown that in Göttingen the pallidum remained the preferred target for Parkinson disease until dopaminergic medication became the mainstay of therapy [D.M., pers. commun.]. In 1967, Levy [14] who had been trained with Riechert in Freiburg as a stipend of the Swiss Academy of Science wrote: "Orthner et al.... continue to regard a meticulously performed pallidoansotomy as the ideal operation for all parkinsonian symptoms provided that the lesions section the majority of the pallidofugal fibres. To this end they place coagulations in the posterior part of the pallidum internum." Roeder [15] wrote: "It is due to the substantial and continuous influence of Ernest Spiegel on the work of our team that we predominantly perform his pallido-ansotomies" (author's translation). During those years, probably only Leksell shared this unfancied opinion [16].

With regard to bilateral pallidotomy performed in Göttingen, Levy [14] elaborates further: "It is also claimed that this operative technique permits bilateral pallidotomy since the main mass of the globus pallidus is spared. Most other authors avoid a bilateral pallidotomy since they fear the neuropsychiatric complications with cognitive deterioration and/or apathy described by Hartmann von Monakov." In his paper, Hartmann von Monakow [17] describes 2 patients with bilateral pallidal lesions as well as 2 patients with lesions in the pallidum and contralaterally in the thalamus (Hassler nucleus ventro-oralis anterior receiving pallidal afferents) exhibiting cognitive and emotional disturbances, hallucinations, and apathy. Hartmann von Monakow refers to similar observations published by Hassler and Riechert [8] and Hassler [18] as well as 3 of 8 early bilateral pallidotomy cases reported by Orthner and Roeder [19]. During that time, Roeder and Orthner refined their targeting of the pallidum, and later Roeder stated: "Our experiences with bilateral pallidotomy are remarkably good. In my opinion the bad experiences of other surgeons (Hassler) are solely attributable to a different surgical technique" (author's translation [15]).

It is interesting to note that the results obtained with bilateral pallidotomy have been extremely variable and conflicting during both the ancient and modern period of pallidotomy. Not only Leksell, who reported good outcome of unilateral pallidotomy, was reluctant to perform bilateral pallidotomy [16], but even in the 1990s, during the resurrection of pallidotomy that was facilitated by MRI guidance, favorable results with bilateral procedures have only been reported on rare occasions [e.g., 20]. In a "Scientific Position Paper of the Movement Disorder Society" evaluating surgical procedures for Parkinson disease, the strength of recommendation for bilateral pallidotomy was "D" ("doubtful”) as "this technology appears to be inappropriate for the given indication" and "risks can be substantial" [21]. 
Fig. 1. The proposed pallidal lesion for the treatment of hemiballism was delineated in a model brain (from Roeder and Orthner [24]). Upper image, axial slice at the intercommissural level (model brain 18/56); the left and right vertical lines are located 3 and $6 \mathrm{~mm}$ posterior to the anterior commissure (AC), respectively. Lower images, coronal slices $3 \mathrm{~mm}$ (left) and $9 \mathrm{~mm}$ (right) posterior to the AC. The vertically hatched areas indicate the lesion from September 10, 1955 , and the horizontally hatched areas the second lesion from January 21, 1956. VC, anterior commissure; HC, posterior commissure; IK, internal capsule; Th, thalamus; NC, caudate nucleus; Pa, pallidum; $\mathrm{Pu}$, putamen; $\mathrm{CM}$, mamillary bodies; $\mathrm{CL}$, subthalamic nucleus; TC, tuber cinerum; II, optic tract; $\mathrm{H}_{0}$, intercommissural plane.
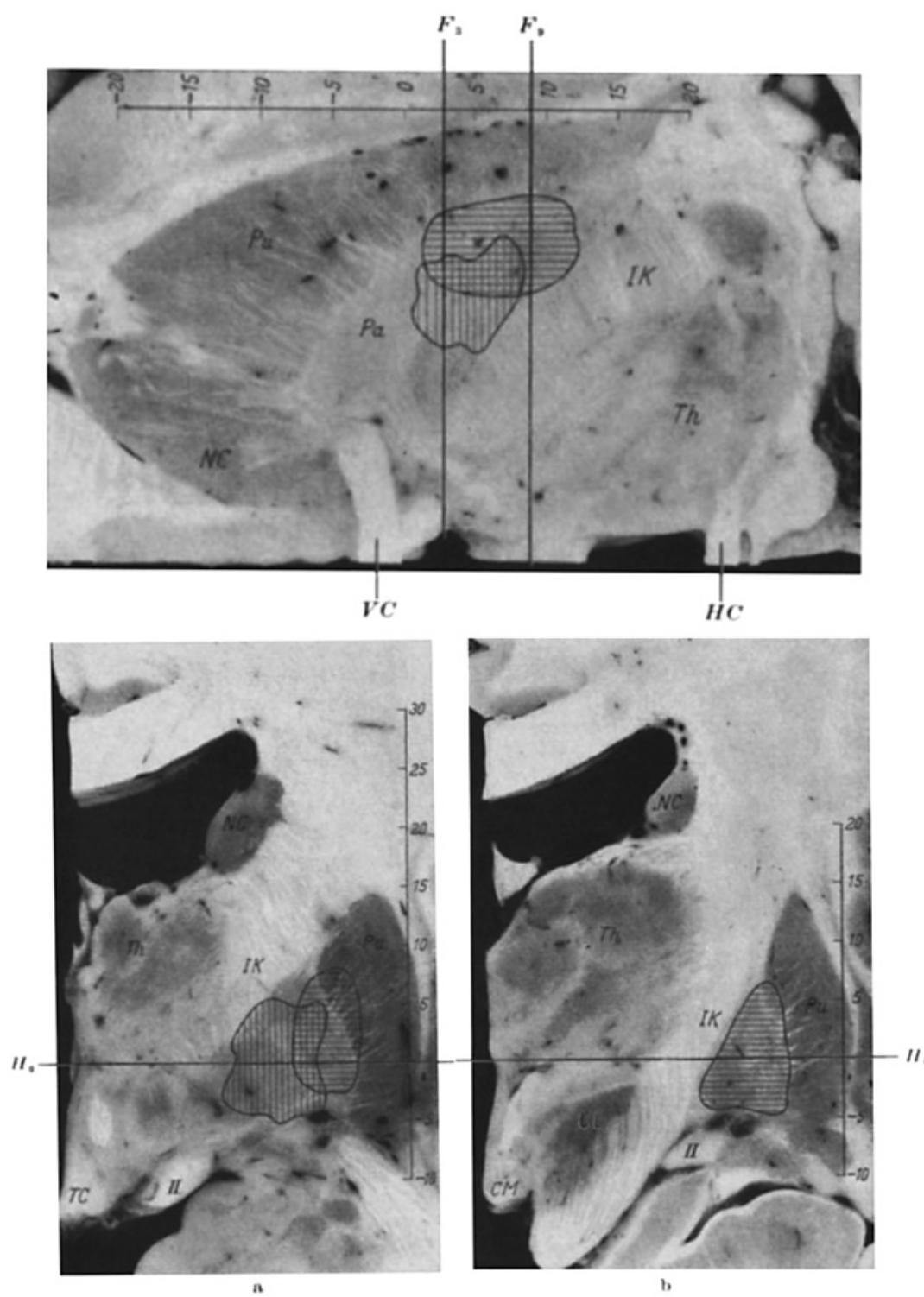

As there has been controversy about bilateral pallidotomy since the early days of stereotactic surgery, it is surprising that a large series of bilateral pallidotomy with systematic pre- and postoperative evaluations including long-term outcome has escaped the attention of most groups performing pallidal surgery until now [22]. Apart from declining interest in pallidotomy among most peers in the 1960s, the fact that relevant publications were written in German by 2 neurologists who were not part of the neurosurgical academic establishment and not quoted by other German authors, in particular from the most influ- ential school of functional stereotaxy in Freiburg, contributed to the oblivion of the work from Göttingen. Hence, a critical appraisal of this instructive work performed by 2 neglected pioneers is overdue.

\section{Target Definition in the Pallidum}

The unique stereotactic approach of the Göttingen group based on head and brain (ventriculographic) measurements and Orthner's stereotactic atlas has been re- 


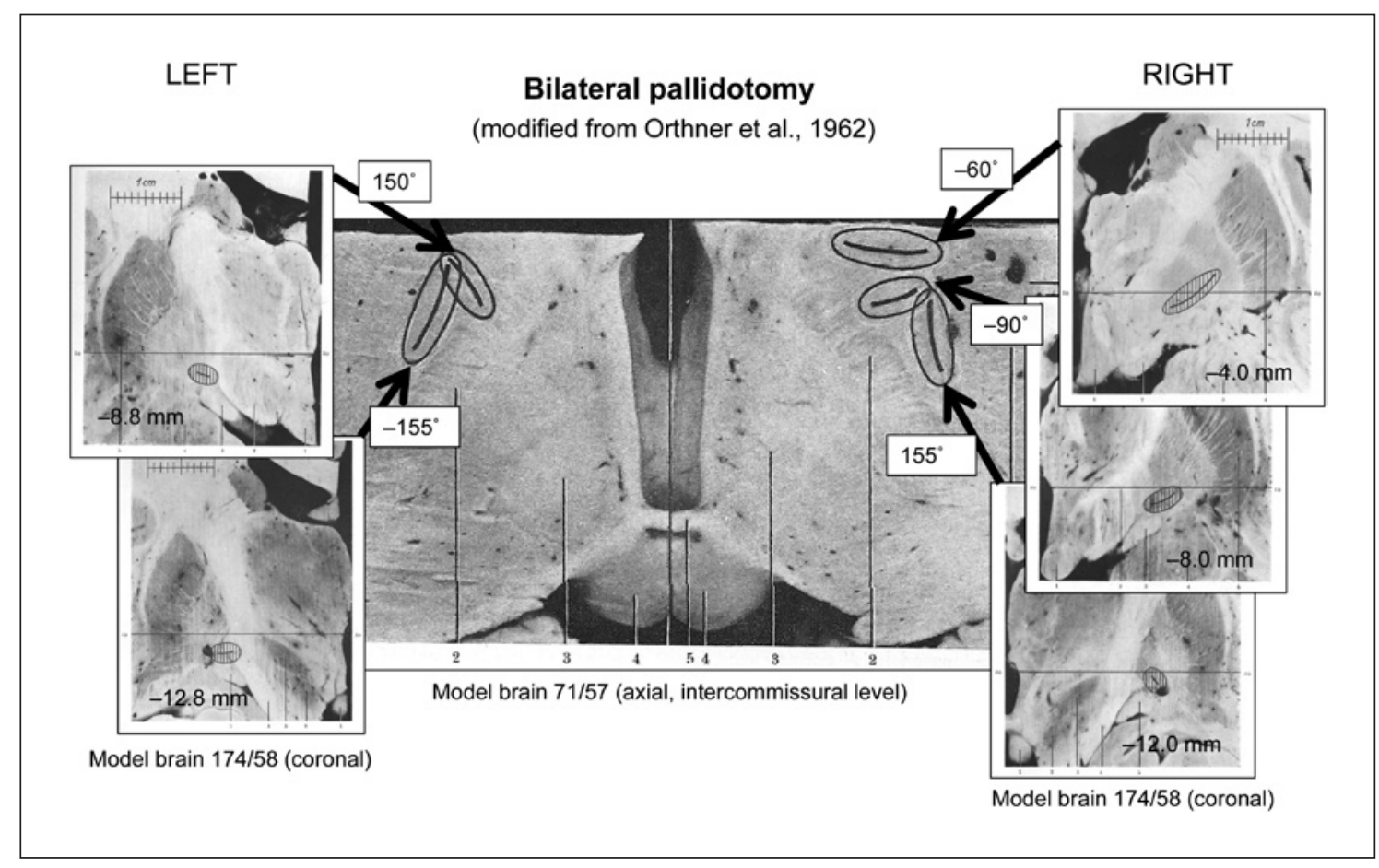

Fig. 2. Planned lesions for bilateral pallidoansotomy in a particular patient (case \#11) are outlined in 2 model brains (71/57, axial; 174/58, coronal; modified from Orthner and Roeder [22]). Coordinates were calculated based on a selected combination of model brains from Orthner's atlas. N.B.: actual coagulations were not performed at exactly the same levels as used for outlining these; thus, some lesions appear to encroach on adjacent structures. Coagulations were still performed with the older generation of noninsulated string electrodes. Thus, later lesions were even more confined. Distances within the images indicate the position of the coronal slice relative to the anterior commissure (AC). Boxes with angles indicate the direction the string electrode was extruded from the carrier probe. Line \#2 in the axial slice indicates the internal capsule. For the right hemisphere, the tip of the probe was initially positioned $5.8 \mathrm{~mm}$ behind the AC (intercommissural length, $23.9 \mathrm{~mm}$ ) and verified by X-ray. The tip of the string electrode was to be extruded in 3 different directions as indicated. Actual stereotactic coordinates for the tip of the extruded insulated electrode were presented in the paper [22]. Coagulations (following test stimulation to confirm correct distance to optic and pyramidal tracts) were performed $2-12.2 \mathrm{~mm}$ behind the AC and 1.7$2.4 \mathrm{~mm}$ below the intercommissural plane. The calculated volume of the intended lesion was $117 \mathrm{~mm}^{3}$ accounting for as little as $5.7 \%$ of the pallidum. Four months later, a left-sided lesion was made. It was directed towards the posterior part of the basal bundle of the ansa lenticularis sparing most of the pallidal mass that was only encroached on in its posteroventromedial aspect. On the left side, only 2 lesions were produced that were located 7.1 and $11.7 \mathrm{~mm}$ behind the AC and 2.7 and $3.1 \mathrm{~mm}$ below the intercommissural plane. The calculated volume was $70 \mathrm{~mm}^{3}$ (3.4\% of the pallidum). viewed in detail [23]. After lessons had been learned from, for example, staged pallidal lesioning for hemiballism [24] (Fig. 1; online suppl. material Pallidotomy for Hemiballism; for all online suppl. material, see www. karger.com/doi/10.1159/000495412), the anatomical target for (bilateral) pallidotomy became confined to the basal bundle of the ansa lenticularis as outlined in Figure 2 [22]. Roeder and Orthner explicitly [15, 25] followed the ansotomy concept of Spiegel and Wycis $[3,26]$. They regarded the pallidum as "structurally intact and healthy," but "hyperactive" and "disinhibited" (authors' translation), and, by reasoning in terms of pathological projection systems, they attempted to interrupt its out- flow [15]. Stimulation and lesioning were made exclusively with string electrodes, although rod (straight needle) electrodes had already become more popular at that time [23] (online suppl. material String Electrodes).

\section{Clinical Outcome}

In the 1960s, there was a lack of standardized and validated rating scales for the assessment of clinical outcome. Roeder and Orthner, who had been trained in clinical neurology, objected to evaluations in rather broad and vague terms that were common at that time (e.g., 
Table 1. Summary of clinical observations and achievements

Detailed single case descriptions for lack of standardized rating scales

First report on long-term improvement in hemiballism by a surgical procedure not resulting in hemiparesis

Intraoperative clinical examination with the detection of loss of rigidity

Improvement in parkinsonian posturing (fingers, arms, knees, and trunk)

Improvement in pain

Improvement in akinesia ("associated movements," such as arm swing during walking, mimic, gestures, repetitive movements)

Improvement in tremor (albeit less effective than

thalamotomy)

Relief from functional disability

Persistence of postural instability; improvement in antero-, latero-, and retropulsion and less falls observed in single patients

Improvement in mood, inhibition, anxiety, compulsions, and restlessness; however, reduced spontaneity

(parkinsonian apathy) may have remained

Improvement in oculogyric crisis

Fine motor skills and "autonomic involuntary harmonic interplay" between muscle groups remained disturbed

fully or partially improved, failure). To this end, the 2 pallidotomy series in Parkinson disease were presented case by case in great detail $([19,22,24]$; summarized in Table 1).

\section{Pallidotomy in Parkinson Disease and Long-Term}

\section{Follow-Up of Bilateral Pallidotomy}

In 1959, Roeder and Orthner provided an exceptionally detailed account of lesion effects in their first series of 57 mainly unilateral pallidotomies in Parkinson disease [19]. Rigidity was relieved almost completely, an effect already noted during surgery. Parkinsonian posturing with flexed fingers, arms, knees, and bent trunk, as well as associated pain were improved. Under the heading of "akinesia," they reported a regular effect on associated movements such as contralateral arm swing when walking and spontaneous associated axial movement of the head and trunk when turning. This was welcomed by the patient not just as an improvement in a sign, but also as a relief from relevant functional disability. Antero-, latero-, and retropulsion could be improved, and patients had less falls. Postural instability, however, could persist de- spite the other improvements. Mimic and gestures became lively again. Relatives noted that patients could smile again. Under the heading "extrapyramidal paresis," the authors reported improvements in dysdiadochokinesia and other repetitive movements. Fine finger movements, such as playing the piano, were not expected to return to normal. It was observed that the normally "autonomic involuntary harmonic interplay" between muscle groups and fine motor skills remained disturbed after pallidotomy despite the improvement in overall voluntary motor functions. Orthner and Roeder observed that pallidotomy-treated parkinsonian patients could be recognized by the fact that they appeared to perform certain movements in a more voluntary manner. This is similar to later observations by Kimber et al. [27]. Speech could be improved, but the authors insisted that they had never seen complete normalization of speech. After bilateral pallidotomy, the speech could become more hypophonic.

From clinical observations, they speculated that pallidotomy delayed the progression of Parkinson disease [15]. According to the authors, the joy of patients who regained independence and experienced functional improvements that would not be achieved with a thalamotomy (e.g., getting up from a chair or turning in bed) prevailed over the disappointment about residual tremor that was not completely relieved. Several renowned stereotactic surgeons had reported less consistent, less sustained, and sometimes delayed suppression of tremor following pallidotomy $[13,28,29]$. Roeder and Orthner stated that tremor suppression usually did not occur instantaneously after pallidal lesioning and that it required larger lesions than those needed for the suppression of rigidity $[15,19]$. However, Roeder and Orthner conceded that the thalamus appears to be the superior target when mere tremor suppression is to be achieved, and later they reported their own series of 111 tremulous patients operated mostly unilaterally $(n=106)$ in the ventrolateral thalamus (Hassler nucleus ventro-intermedius) $[15,30]$.

Concerning psychiatric effects, the most frequently observed effect was an improvement in mood. The authors (both were also trained neuropsychiatrists) described improvements in inhibition, anxiety, compulsions, and restlessness as specific effects of pallidotomy (note that some of the patients were postencephalitic patients and these psychic symptoms were prominent in the pre-levodopa era). In contrast, reduced spontaneity (parkinsonian apathy) was not influenced.

In 1962, the long-term effects (3-year follow-up on average) of the first 18 of 36 patients with staged bilateral 

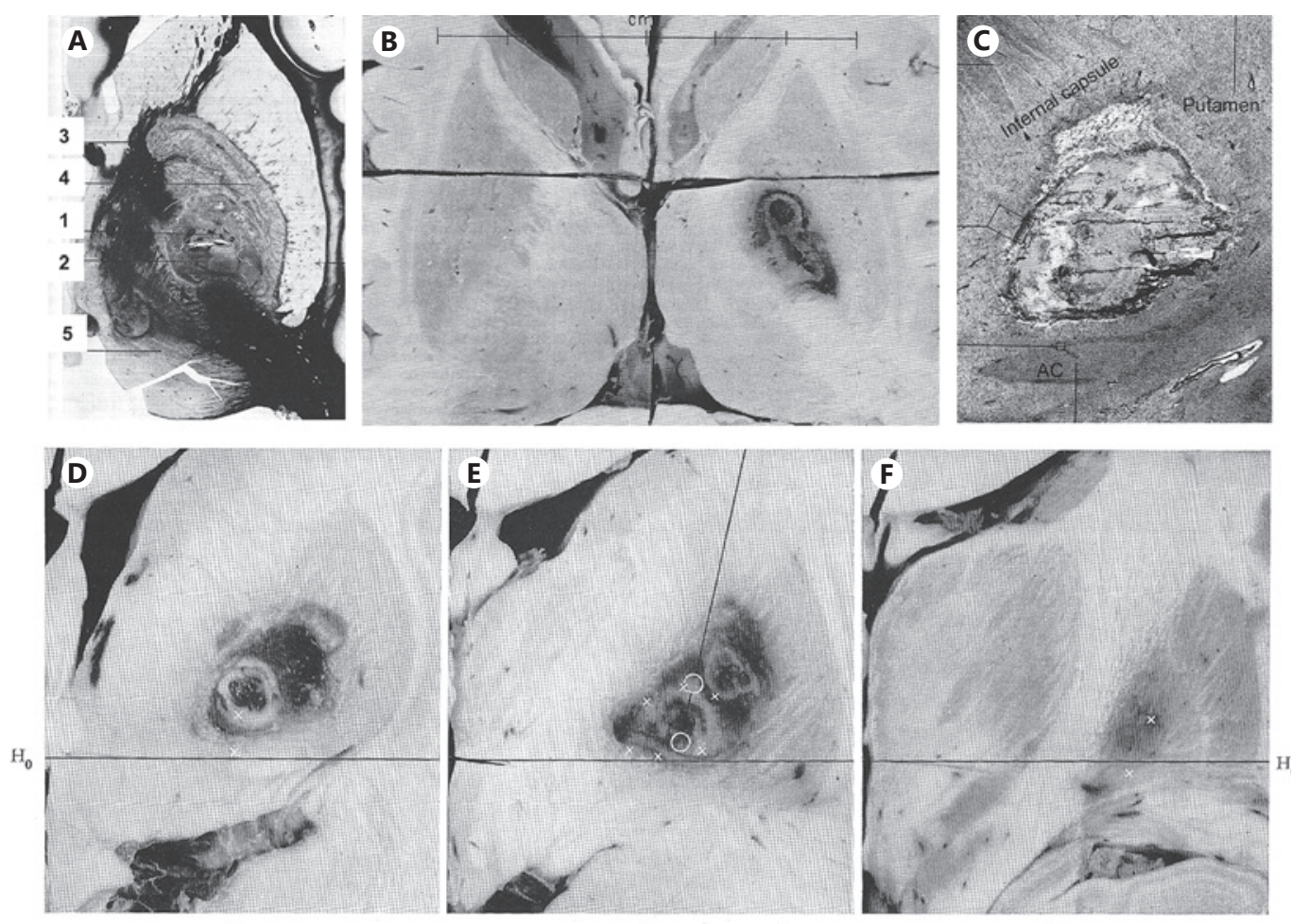

$\mathrm{F}_{0}$

$\mathrm{F}_{6}$

$F_{12}$

Fig. 3. Postmortem examination following pallidotomy (from Orthner and Roeder [19]). A Horizontal section $3 \mathrm{~mm}$ dorsal to the intercommissural plane reveals the maximum extension of the lesion. Death from bronchopneumonia occurred 11 days following pallidotomy on October 13, 1956 (male; 58 years; case \#2). Additional autoptic findings were chronic obstructive lung disease and kidney metastasis of unknown primary. On day 4 after surgery, leg weakness developed but practically no brachiofacial paresis. The lesion (1) was found in proper position in the posterior part of the medial pallidum. In addition, a hemorrhage (2) extending into the internal capsule had developed. Also indicated are the genu of the internal capsule (3), external pallidum (4), and thalamus (5). B An axial section $5 \mathrm{~mm}$ dorsal to the intercommissural plane (intercommissural length $24.5 \mathrm{~mm}$ ) is shown. Death from bronchopneumonia occurred 6 days after pallidotomy on September 10, 1957 (male; 60 years; case \#19) [19]. There was comorbidity with obesity and atherosclerosis. Stupor, mutism, and apathy, but not paresis, developed postoperatively. Tremor and rigidity were alleviated. The actual lesion (6 coagulations) did not deviate

pallidotomies were reported in great detail [22]. The paper written in German contains abstracts in English, French, Italian, and Spanish, and thus it was made accessible to a large public. Akinesia, rigidity, and tremor were improved. Postural instability could be improved, but this was not always the case. Speech, drooling, and sebor- from the planned lesion. Approximately $2 / 5$ of the pallidum were destroyed. A rim of slight hemorrhage and edema was detected around the lesion. C-F Case \#11 [19] is presented. D-F Coronal slices 0,6 , and $12 \mathrm{~mm}$ posterior to the anterior commissure (AC), respectively. Acute pulmonary embolism led to sudden death 18 days after pallidotomy on April 21, 1957 (female; 50 years; case \#11). There was postoperative stupor, mutism, depression, but not paresis. Rigidity and tremor had improved. Approximately $2 / 3$ of the pallidum $\left(1,550 \mathrm{~mm}^{3}\right)$ had been destroyed. The lesion slightly encroached on the putamen and internal capsule. Circles (in $\mathbf{E}$ ) represent projections of the tip of the carrier probe (2 positions) onto the slice that is located $6 \mathrm{~mm}$ posterior to the AC (N.B.: all procedures involved only 1 trajectory). Markings with a cross (x) indicate the tip of the extruded (older generation noninsulated) string electrode. Due to severe parkinsonism, an unusually high number (10) of coagulations had been placed $0.5-10.7 \mathrm{~mm}$ behind the AC (AC-PC length $24 \mathrm{~mm}$ ). The lesion deviated about $1 \mathrm{~mm}$ each direction $(x, y, z)$. $\mathrm{H}_{0}$, intercommissural plane; intercommissural length $23.5 \mathrm{~mm}$. 
Table 2. Adverse events and surgical complications following pallidotomy

\begin{tabular}{|c|c|}
\hline Death & $\begin{array}{l}3 \text { of } 95 \text { patients }(3.2 \%) \\
0 \text { of } 36 \text { patients with bilateral } \\
\text { pallidotomy }\end{array}$ \\
\hline $\begin{array}{l}\text { Intracranial } \\
\text { hemorrhage }\end{array}$ & $\begin{array}{l}1 \text { of } 95 \text { patients }(1.1 \%) \\
\text { paresis of the left leg, death from } \\
\text { pneumonia and detection of carcinoma } \\
\text { (case } \# 2 \text { in }[19] \text { ) }\end{array}$ \\
\hline Visual field defects & 0 of 95 patients \\
\hline Paresis & $\begin{array}{l}6 \text { of } 95 \text { patients }(6.3 \%) \\
3 \text { patients with bilateral pallidotomy }\end{array}$ \\
\hline $\begin{array}{l}\text { Drive disorder, } \\
\text { apathy, and } \\
\text { stuporous states }\end{array}$ & $\begin{array}{l}12 \text { of } 95 \text { patients ( } 12.6 \%) \text {, including } 4 \text { of } 36 \\
\text { patients having undergone bilateral } \\
\text { pallidotomy (mostly earlier cases with larger } \\
\text { lesions) }\end{array}$ \\
\hline
\end{tabular}

Rates according to Orthner and Roeder [19, 22].

The clinical improvement in 1 patient (patient \#11 [22]; lesion outlined in Fig. 2) was also assessed by a fiduciary physician who examined this patient after the first procedure and attested: "The unilateral procedure on the right side resulted in a complete relief of rigidity and tremor on the left side. Mr. R. is a lot more liberated in his movements and behaviour." After the second procedure, he wrote: "After being incapable of working and being nursed at home for 5 years the patient resumed working as a parking attendant at a shipyard in Hamburg. After his company filed bankruptcy he immediately found a new well-paid job" (authors' translation; [22]).

\section{Complication Rates}

Complication rates are of particular relevance for an appraisal of clinical achievements in functional neurosurgery, since the overriding principle of its practice is "primum non nocere." According to the meticulous case descriptions, complication rates of the Göttingen group met the highest standards at their time (summarized in Table 2; cf. online suppl. material Adverse Events for a detailed workup of surgical complication rates as well as neurological and psychiatric adverse events including a comparison of the literature).

Their rates for postoperative mortality, hemorrhages, visual field defects, hemiparesis, and psychiatric adverse events also compare favorably with those reported in the modern era of pallidotomy already blessed with CT/MRI guidance and other technical innovations [reviewed in 32, 33]. Apart from the Göttingen group, only few centers have accomplished bilateral pallidotomy with acceptable complication rates [20].

Low rates of complications were essential for the Göttingen group. The University kept a wary eye on this group as some of the faculty members had not been in favor of this off-campus stereotactic program run by 2 neurologists [D.M. and Mrs. Orthner, pers. commun.].

\section{Postmortem Studies}

In the beginning, pallidal lesions of the Göttingen stereotactic group were rather large (online suppl. material Pallidotomy for Hemiballism). In a severely affected patient with a parkinsonian syndrome (case \#11; [19]), an unusually high number of coagulations $(n=10)$ had been placed, which probably contributed to the stuporous state and ensuing death (Fig. 3c-f).

In another case (\#19; [19]) medial and posterior parts of the internal pallidum were lesioned by 6 coagulations (Fig. 3b). The total lesion encompassed about $2 / 5$ of the pallidum and extended posterior to the midcommissural point. The internal capsule was spared. In another case, a proper pallidal lesion went along with a possibly delayed hemorrhage extending into the internal capsule (Fig. 3a).

In 1966, Orthner and Roeder [19] reported on a previously described patient (case \#48) who died 3 years after pallidotomy [31]. In Figure 4, the shrunken lesion with secondary degeneration of the ansa lenticularis can be seen at different levels $(0,4$, and $8 \mathrm{~mm})$ behind the anterior commissure (AC). Compared to the nonoperated side, the volume of the lesioned pallidum was reduced by $530 \mathrm{~mm}^{3}$.

In all the cases mentioned so far, the authors had produced rather large lesions. To some extent, this was unavoidable by the use of uninsulated string electrodes (until April 1961, i.e., including the series of 18 patients with bilateral pallidotomies with detailed long-term followup). Until then, they attempted to destroy the medial and posterior part of the internal pallidum and had not condensed lesions to their pallidoansotomy target yet.

In 1963, Orthner [25] presented a postmortem analysis exhibiting a lesion at the basocaudal bundle of the ansa lenticularis only (Fig. 5) [15, 25]. The authors pointed out that the correct term for this procedure is pallidoansotomy as the ansa lenticularis can only be safely destroyed within the pallidum. The lesion measured $135 \mathrm{~mm}^{3}$, corresponding to $7.9 \%$ of the left pallidum, and it extends 


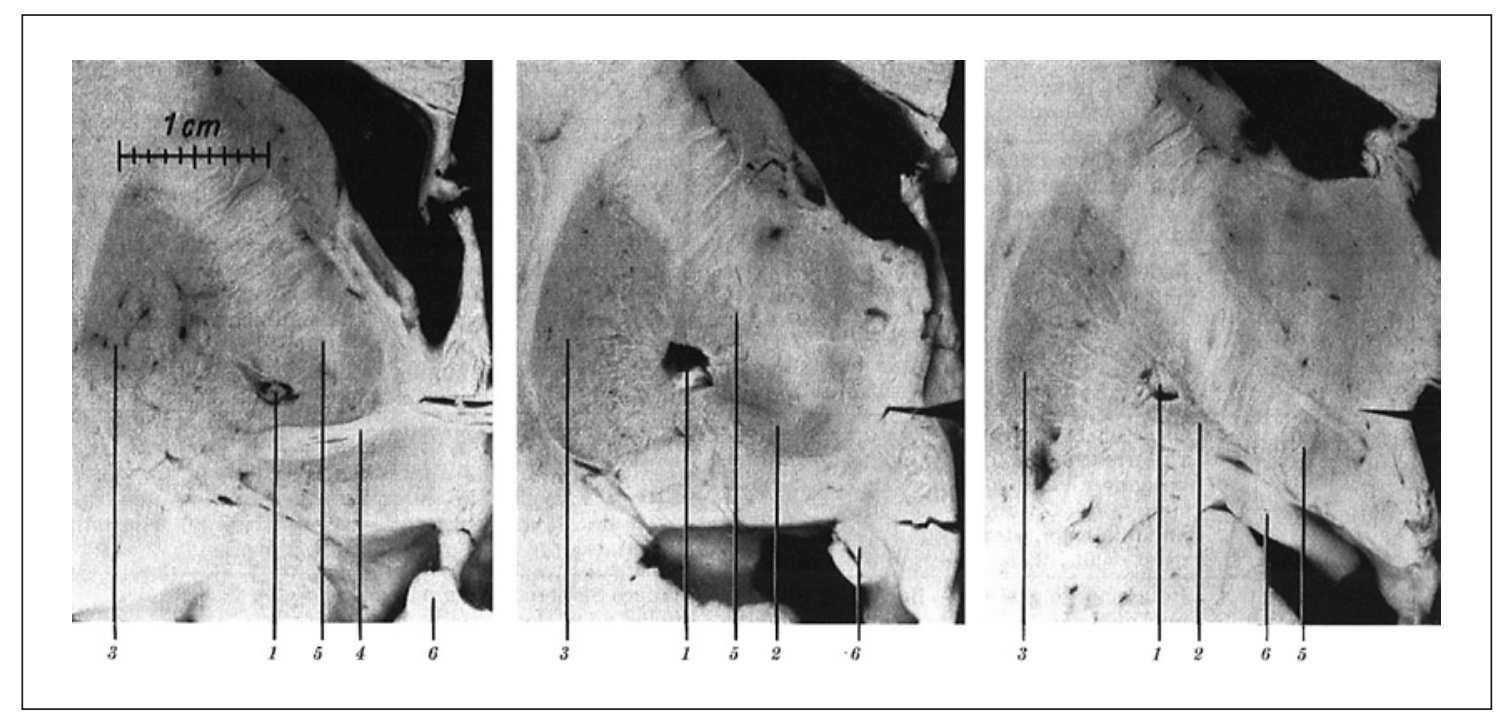

Fig. 4. Postmortem examination following pallidotomy. Coronal slices (from left to right) were located 0,4 , and $8 \mathrm{~mm}$ posterior to the anterior commissure (AC). Pallidotomy had been performed on July 2, 1958, placing 3 coagulations in an attempt to destroy about $2 / 5$ of the primarily internal segment [19]. Death occurred 3 years after pallidotomy from hemorrhagic pneumonia (52-year- old male at surgery; representing case \#5 in [31] and case \#48 in [19]). The shrunken lesion (1) in the center of the left medial pallidum resulted in degeneration of the ansa lenticularis. Surgery resulted in sustained motor improvement and alleviation of oculogyric crisis. No injury to the internal capsule (5) and optic tract (6). Also indicated are putamen (3) and AC (4).
$>9.3 \mathrm{~mm}$ behind the AC. According to the authors, tremor and other parkinsonian symptoms had improved markedly. In both hemispheres, the pallidum was found to be enlarged compared to age-matched females, a common finding in Parkinson disease patients according to previous volumetric studies [34, 35].

In 1974, a shrunken pallidal lesion performed 37 months prior to a contralateral ventrolateral thalamotomy has been reported (Fig. 5) [30]. The pallidal lesion is confined to the mediobasal border of the internal pallidum and adjacent ansa lenticularis sparing the internal capsule and optic tract (Fig. 5). According to the authors, the lesion had an excellent effect on left-sided parkinsonian symptoms [30]. Notably, the pallidal lesion is found on a brain section $8.4 \mathrm{~mm}$ anterior to the posterior commissure (PC). Even without knowledge of AC-PC length, this location must be posterior to the midcommissural point. It is possible that the authors have moved the target even more posteriorly over time. Unfortunately, the whole extent and volume of the lesion has not been demonstrated. The precision of their surgical approach can also be appreciated in the case of a ventrolateral thalamotomy for torticollis exhibiting a sharp border to the unaffected internal capsule (Fig. 5) [15, 30].

Taken together, these observations demonstrate that the authors performed posterior and ventral lesioning of the pallidum. Thus, lesions were placed in a position similar to the contemporary target worked out by Leksell and his group [36]. How variable targeting was in the 1960s among different workers is exemplified in a detailed postmortem study of Hanieh and Maloney [37] revealing more anterior and dorsal lesions in the pallidum (on average $7 \mathrm{~mm}$ anterior and $1.5 \mathrm{~mm}$ superior to the midcommissural point).

\section{Conclusion}

The Göttingen school's accomplishment of true pallidoansotomy eventually resulting in a large series of bilateral pallidotomy with meticulous pre- and postoperative evaluations and excellent long-term outcomes has escaped the attention of most groups performing pallidal surgery until now. Several aspects are remarkable even in retrospect. Roeder and Orthner recognized the merits of posteroventral pallidotomy on parkinsonian symptoms, in particular akinesia and rigidity translating into improved motor functioning. This emphasizes the thoroughness of their clinical evaluation and independent thinking. All the findings reported by the authors in the 1950 s and early 1960s have been replicated in the new era of pallidotomy with a boom in the 1990s based on revisit- 


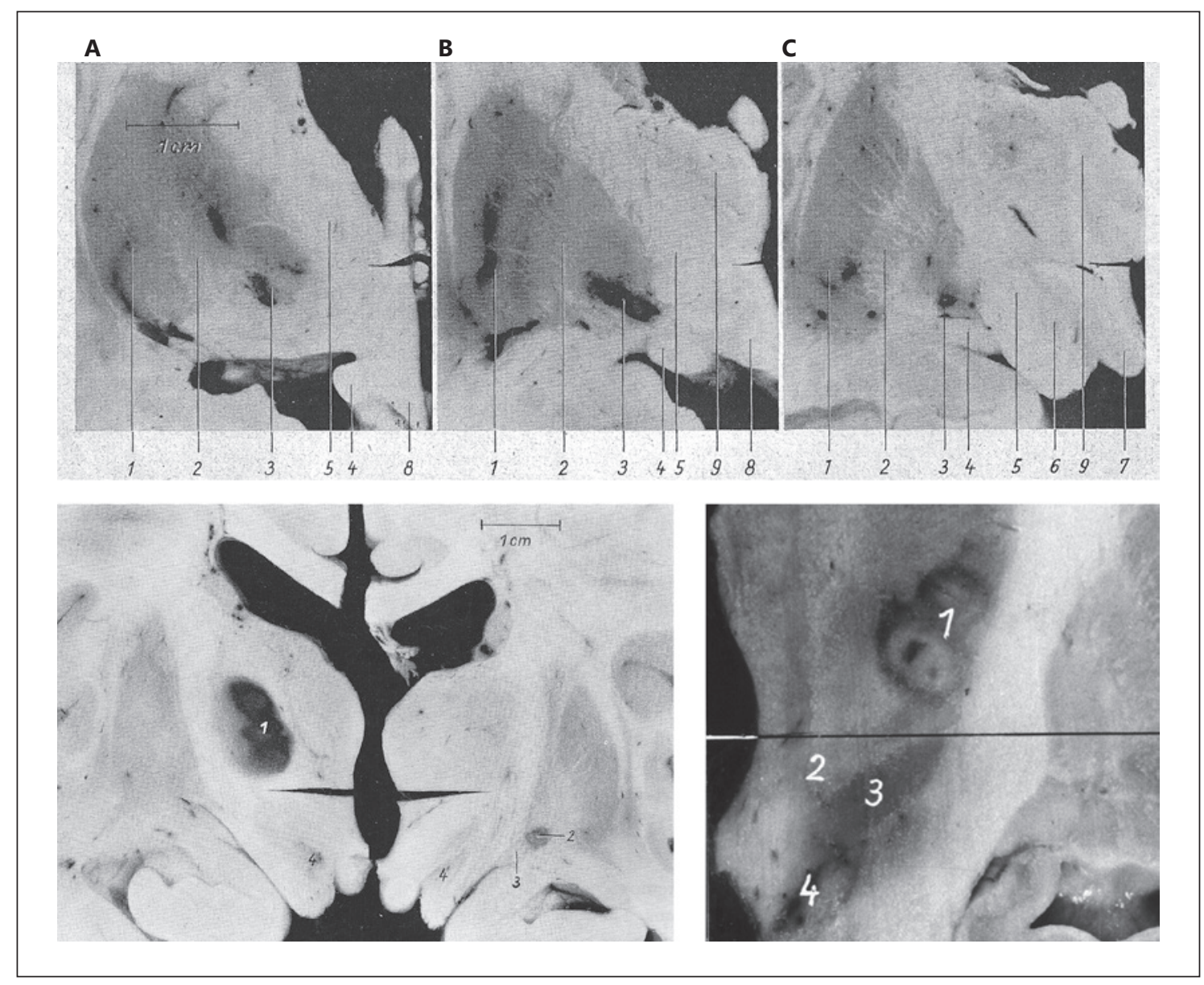

Fig. 5. Postmortem examination following pallidotomy and thalamotomy in Parkinson disease. A-C Coronal slices located 1.3, 5.3, and $9.3 \mathrm{~mm}$ posterior to the anterior commissure. A severely affected postencephalitic parkinsonian patient had received unilateral pallidotomy on September 14, 1961. After a collaptic event 10 days after surgery, she died on September 30, 1961, from pneumonia, pulmonary embolism, and circulatory failure (64 years; case \#2 in [25]). This lesion (3) was produced with the new generation of insulated string electrodes and only encompassed the basocaudal bundle of the ansa lenticularis. B Maximal extent of the lesion. Volumetric analysis revealed a lesion size of only $135 \mathrm{~mm}^{3}$ corresponding to $7.9 \%$ of pallidum. Notably, this represents a rather acute lesion before consolidation and shrinking. Based on the known volume of coagulation with insulated string electrodes, we speculate that $4-5$ lesions had been performed. Both pallida were enlarged in comparison to age-matched females (left pallidum after lesion, $1,710 \mathrm{~mm}^{3}$; right $1,982 \mathrm{~mm}^{3}$ ). Wallerian degeneration of the ansa lenticularis had been detected in adjacent slices (not shown). There was no injury to critical adjacent structures, in par-

ing Leksell's pallidotomy by Laitinen et al. [36], a new model of basal ganglion pathophysiology [38], the motor complications of levodopa treatment, and progress in stereotaxy mainly based on new imaging tools [39]. The only ticular, the internal capsule (5) and optic tract (4). In addition, the putamen (1), external pallidum (2), anterior portion of degenerated substantia nigra (2), mamillary bodies (7), tuber cinerum (8), and thalamus (9) are indicated. The left lower image represents a coronal section $8.4 \mathrm{~mm}$ in front of the posterior commissure. Death in a 61-year-old female had occurred from circulatory failure 5 days after thalamotomy; the lesion is indicated (1) [30]. Thirty-seven months previously, a contralateral pallidotomy (selective pallidoansotomy) had been conducted "with excellent effect on the left-sided symptoms." The shrunken lesion (2) is seen at the apex of the pallidum close to but in due distance from the optic tract (3). The degenerated substantia nigra is indicated (4). The lower right image provides additional proof for the precision of lesioning. In this case, a ventrolateral thalamotomy ( 1 indicates the lesion) had been performed for torticollis in a 63-year-old female. A coronal slice $9.9 \mathrm{~mm}$ in front of the posterior commissure is shown. Death occurred 3 weeks after surgery from pneumonia and pulmonary embolism. The fields of Forel (2), subthalamic nucleus (3), and substantia nigra (4) are indicated. clinical benefit of pallidotomy in Parkinson disease that the Göttingen group had not described was the effect on levodopa-induced dyskinesia because the work took place in the pre-levodopa era. However, the authors did de- 
scribe a benefit of pallidotomy on the choreic movements in hemiballism and on dystonia in oculogyric crisis in parkinsonism, and they also used pallidotomy as a surgical treatment for focal or generalized dystonia. Complication rates compare very favorably with the pre- and postlevodopa era of pallidotomy. Their unique stereotactic technique was a prerequisite for the safe performance of staged bilateral pallidotomies that had been dismissed by most groups because of unacceptable complication rates. From postmortem studies, there is evidence that Orthner and Roeder have accomplished selective and individually tailored lesioning of the posterior and ventral pallidum and the ansa lenticularis (pallidoansotomy).

\section{Acknowledgments}

We are indebted to Mrs. A. Orthner who was involved in stereotactic calculations and in the preparation of the brain atlas and postmortem examinations since 1962, and to Prof. R. Meyermann and Dr. A. Argyrakis, both former fellows of Prof. Roeder and Prof. Orthner, for providing us with many invaluable hints and important background information. We are grateful to Mrs. U. Vogel for allowing one of the authors (C.K.E.M.) to inspect the correspondence of her father, F.D. Roeder.

\section{Disclosure Statement}

The authors have nothing to disclose.

\section{References}

1 Meyers R. The modification of alternating tremors, rigidity and festination by surgery of the basal ganglia. In: Putnam TJ, Frantz AM, Ranson SW, editors. The diseases of the basal ganglia. Baltimore: Williams \& Wilkins; 1942. p. 602-65.

2 Narabayashi H, Okuma T, Shikiba S. Procaine oil blocking of the globus pallidus for the treatment of rigidity and tremor or parkinsonism. Arch Neurol Psychiatry. 1956;75:3648.

3 Spiegel EA, Wycis HT. Ansotomy in paralysis agitans. AMA Arch Neurol Psychiatry. 1954 May;71(5):598-614.

4 Riechert T, Wolff M: Die technische Durchführung von gezielten Hirnoperationen. Arch Psychiatr Nervenkr Z Gesamte Neurol Psychiatr. 1953;190(4):297-316.

5 Riechert T. Stereotaktische Operationen bei Bewegungsstörungen. Dtsch Z Nervenheilkd. 1957;175(5):511-9.

6 Guiot G, Brion S. Traitement neurochirurgical de syndromes choréo-athétosique et Parkinsonien. Sem Hop. 1952 Jul;28(49):2095-9.

7 Cooper IS, Bravo G. Chemopallidectomy and chemothalamectomy. J Neurosurg. 1958 May; 15(3):244-50.

8 Hassler R, Riechert T. Indikationen und Lokalisationsmethode der Hirnoperationen. Nervenarzt. 1954 Nov;25(11):441-7.

9 Krauss JK, Grossman RG. Historical review of pallidal surgery for treatment of parkinsonism and other movement disorders. In: Krauss JK, Grossman RG, Jankovic J, editors. Pallidal surgery for the treatment of parkinson's disease and movement disorders. Philadelphia: Lippincott-Raven; 1998. p. 1-23.

10 Schaltenbrand G, Walker AE. Stereotaxy of the human brain. New York: Thieme; 1982.

11 Mundinger F. Foreword. In: Krauss JK, Grossman RG, Jankovic J, editors. Pallidal surgery for the treatment of parkinson's disease and movement disorders. Philadelphia, New York: Lippincott-Raven; 1998. p. xvii.
12 Hoehn MM, Yahr MD. Evaluation of the long term results of surgical therapy; in Gillingham FJ, Donaldson IML (eds): Third Symposium on Parkinson's Disease, Livingstone, 1969, p. 274-280.

13 Mundinger F, Riechert T. Ergebnisse der stereotaktischen Hirnoperationen bei extrapyramidalen Bewegungsstörungen auf Grund postoperativer und Langzeituntersuchungen. Dtsch Z Nervenheilkd. 1961;182(5):542-76.

14 Levy A. Stereotaxic brain operations in Parkinson's syndrome and related motor disturbances. Comparison of lesions in the pallidum and thalamus with those in the internal capsule. Confin Neurol. 1967;29:Suppl:1-70.

15 Roeder F. Über die maximale Behandlung des Parkinsonsyndroms. Wiss Beibl Mat Med Nordmark. 1967;59:1-46.

16 Svennilson E, Torvik A, Lowe R, Leksell L. Treatment of parkinsonism by stereotatic thermolesions in the pallidal region. A clinical evaluation of 81 cases. Acta Psychiatr Scand. 1960;35(3):358-77.

17 Hartmann von Monakow K. Halluzinosen nach doppelseitiger stereotaktischer Operation bei Parkinson-Kranken. Arch Psychiatr. 1959;199(5):477-86.

18 Hassler R: Extrapyramidal-motorische Syndrome und Erkrankungen; Handbuch der inneren Medizin. Berlin: Springer; 1953. vol. $\mathrm{V} / 3$, p. 676.

19 Orthner H, Roeder F. Das Parkinson-Syndrom und seine Behandlung durch Elektrokoagulation des Globus pallidus. II. Mitteilung. Stuttgart: Fischer; 1959.

20 Iacono RP, Shima F, Lonser RR, Kuniyoshi S, Maeda G, Yamada S. The results, indications, and physiology of posteroventral pallidotomy for patients with Parkinson's disease. Neurosurgery. 1995 Jun;36(6):1118-25.
21 Hallett M, Litvan I. Scientific position paper of the Movement Disorder Society evaluation of surgery for Parkinson's disease. Task Force on Surgery for Parkinson's Disease of the American Academy of Neurology Therapeutic and Technology Assessment Committee. Mov Disord. 2000 May;15(3):436-8.

22 Orthner H, Roeder F. [Experiences with stereotactic surgery. IV. On the long-term effect of bilateral pallidotomy in Parkinson's syndrome]. Acta Neurochir (Wien). 1962 Dec; 10:572-629.

23 Hamel W, Köppen JA, Hariz M, Krack P, Moll CK. The pioneering and unknown stereotactic approach of Roeder and Orthner from Göttingen. Part I. Surgical technique for tailoring individualized stereotactic lesions. Stereotact Funct Neurosurg. 2016;94(4):240-53.

24 Roeder F, Orthner H. Erfahrungen mit stereotaktischen Eingriffen. I. Mitteilung. Zur Pathogenese und Therapie extrapyramidalmotorischer Bewegungsstörungen. Erfolgreiche Behandlung eines Falles von schwerem Hemiballismus mit gezielter Elektrokoagulation des Globus pallidus. Dtsch Z Nervenheilkd. 1956;175:419-34.

25 Orthner H: Stereotaktische Eingriffe im Gehirn. Sonderdruck aus DZK (Heidelberger Fortbildungstage 1962) 1963;9:345-359.

26 Wycis HT, Spiegel EA. Ansotomy in paralysis agitans. Confin Neurol. 1952;12(4):245-6.

27 Kimber TE, Tsai CS, Semmler J, Brophy BP, Thompson PD. Voluntary movement after pallidotomy in severe Parkinson's disease. Brain. 1999 May;122(Pt 5):895-906.

28 Krayenbuehl H, Yasargil MG. Ergebnisse der stereotaktischen Operationen beim Parkinsonismus, insbesondere der doppelseitigen Eingriffe. Dtsch Z Nervenheilkd. 1961;182:530-41.

29 Hassler R. Ueber die Bedeutung der pallidären Systeme für Parkinsonsyndrom und Psychomotorik nach Erfahrungen bei gezielten Hirnoperationen: 1st International Congress of Neurosurgery. Brussels, 1957, 1, p. 171-178. 
30 Meyermann R, Müller D, Orthner H, Roeder F. The tremorigenic area of the thalamus. Therapeutic implications in stereotactic neurosurgery of extrapyramidal motor disturbances. In: Umbach W, Koepchen HP, editors. Central-rhythmic and regulation. Stuttgart: Hippocrates-Verlag; 1974. p. 391-6.

31 Orthner H. Die Beeinflussung der postencephalitischen Schauanfälle durch die Pallidotomie. Nervenarzt. 1966 Jul;37(7):317-9.

32 Alkhani A, Lozano AM. Pallidotomy for Parkinson disease: a review of contemporary literature. J Neurosurg. 2001 Jan;94(1):43-9.
33 de Bie RM, de Haan RJ, Schuurman PR, Esselink RA, Bosch DA, Speelman JD. Morbidity and mortality following pallidotomy in Parkinson's disease: a systematic review. Neurology. 2002 Apr;58(7):1008-12.

34 Orthner H, Sendler W. [Some results of macroscopic-quantitative brain research]. Verh Dtsch Ges Pathol. 1968;52:243-50. German.

35 Orthner H, Seler W. [Planimetric volumetry of human brains]. Fortschr Neurol Psychiatr Grenzgeb. 1975 Apr;43(4):191-209.

36 Laitinen LV, Bergenheim AT, Hariz MI. Leksell's posteroventral pallidotomy in the treatment of Parkinson's disease. J Neurosurg. 1992 Jan;76(1):53-61.
37 Hanieh A, Maloney AF. Localization of stereotaxic lesions in the treatment of Parkinsonism: a clinico-pathological comparison. J Neurosurg. 1969 Oct;31(4):393-9.

38 Alexander GE, Crutcher MD, DeLong MR. Basal ganglia-thalamocortical circuits: parallel substrates for motor, oculomotor, "prefrontal" and "limbic" functions. Prog Brain Res. 1990;85:119-46.

39 Vitek JL, Bakay RA, Hashimoto T, Kaneoke Y, Mewes K, Zhang JY, et al. Microelectrodeguided pallidotomy: technical approach and its application in medically intractable Parkinson's disease. J Neurosurg. 1998 Jun;88(6): 1027-43. 